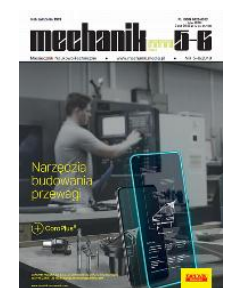

\author{
How to cite this article: \\ Authors: Jakub Sikorski \\ Title of article: „Pneumatic actuator supported with hydraulic system” \\ Mechanik, No. 5-6 (2019) \\ DOI: https://doi.org/10.17814/mechanik.2019.5-6.42
}

\title{
Pneumatic actuator supported with hydraulic system
}

\section{JAKUB SIKORSKI*}

Mgr inż. Jakub Sikorski, jakub.sikorski@p.lodz.pl, https://orcid.org/0000-0001-5979-0498 - Instytut Obrabiarek i Technologii Budowy Maszyn, Politechnika Łódzka, Łódź, Polska

A design experiment involving the addition of the hydraulic line to the pneumatic cylinder to trigger dynamic phenomena in the cylinder is presented. Thanks to this, it is possible to limit the occurrence of the stick-slip phenomenon, often occurring in linear actuators at a low mutual speed of the piston and the cylinder. The purpose of this operation is to obtain the possibility of precise control of the piston position of the pneumatic cylinder without using complicated systems using algorithms with nonlinear functions.

KEYWORDS: actuator, stick-slip, pneumatic, hydraulic

\section{Introduction}

Pneumatic or hydraulic drives are often used in machines, but usually active pneumatic and hydraulic systems are not placed in one device. This is due to avoiding unnecessary complications in the structure. In typical pneumo-hydraulic solutions, the pneumatic (active) part is the drive, while the hydraulic (passive) part is used to regulate the propulsion system speed. However, there are constructions, in which both active systems are combined to achieve the desired operation of the mechanism.

In the construction of pneumatic actuators, more and more sealing and guiding elements for piston and piston rod are used. At the same time, the requirements for the surface roughness of cylinders and piston rods cooperating with seals and guides are increasing $[2,5,9]$. This is to extend the trouble-free operation of devices containing these elements, but does not eliminate the adverse friction that occurs during the actuator's operation, e.g. stick-slip phenomena.

The stick-slip phenomenon makes it difficult to precisely control the speed and positioning of a pneumatic actuator at low relative speeds between the piston and the cylinder. To counteract this, it is necessary to determine the non-linear friction characteristics of the actuator and express it using a mathematical model. In addition, if the mathematical model of the friction characteristics is fully determined, the dynamic behavior of the actuator can be accurately predicted already at the design stage of the device [10].

The occurrence of friction in a pneumatic actuator depends on many factors. These include: actuator design, cylinder piston direction of movement, and grease viscosity. Control over the work of the actuator is additionally hindered by the compressibility of the working medium, which is air. Taking into account the impact of all these factors on the operation of a pneumatic actuator is necessary to develop a control system, in which negative phenomena resulting from friction characteristics are compensated and which allows the use of a pneumatic actuator as an element of precise servomotor $[1,10]$.

Designing a control system to compensate for the stick-slip phenomenon is complicated. As shown, linear control algorithms do not apply in this case, as the stick-slip phenomenon itself is non-linear. It is necessary to use algorithms containing nonlinear functions $[3,10]$. Eliminating or significantly reducing the stick-slip phenomenon in a pneumatic actuator would simplify the control system.

Currently used pneumatic actuators work properly when moving seals on sliding surfaces. However, each stopping of the actuator causes the unfavorable phenomenon of the seals sticking to the sliding surfaces, which increases with the extension of the actuator stopping time. This is due to the lubricant being squeezed 
out between the sealing surfaces and the sliding elements, which is due to the elasticity of the sealing element [6].

The paper presents a new design of a pneumatic actuator, in which the adverse phenomenon of sealing adhesion to sliding surfaces has been reduced. An additional hydraulic system was supplied to the pneumatic actuator. Due to a specially developed servomotor, it is supposed to limit the sticking of piston seals and thus eliminate the stick-slip phenomenon.

\section{Construction description}

The mechanism was designed in Autodesk Inventor Professional. It is a parametric program that allows three-dimensional design of parts. They can be assembled into components and entire machines. The program has a number of functionalities that facilitate the design of devices, including for collision analysis of components, kinematics and dynamics (to control the cooperation of components) and for the analysis of strength using the finite element method. It is possible to measure the deformation of elements under the influence of external forces, which allows to determine the effect of hydraulic fluid pressure on the cylinder parts $[4,7]$.

Fig. 1 shows the longitudinal section of the subassembly in the plane passing through the cylinder axis of the pneumatic actuator. The mechanism consists of a cylinder (1) and an inner cylinder (2) inserted in it, in which the rear cover (3) and the front cover (4) are mounted, detachably connected to the cylinder (1) by means of screws (5). The front cover (4) has an axially located hole and a seat with a piston rod (6) mounted in them. The end of the piston rod (6) was placed in the inner cylinder (2) and connected to the piston (7) by means of the nut (8) screwed on the end of the piston rod [6].

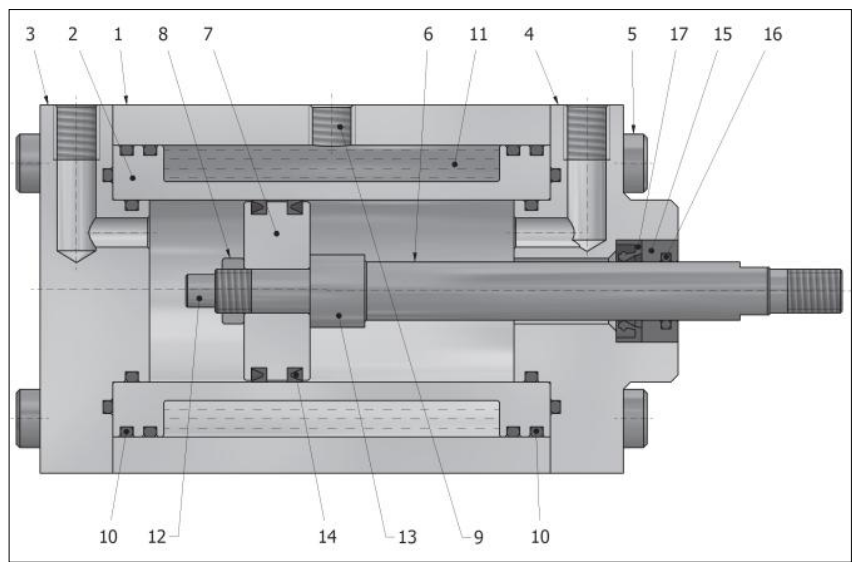

$\triangle$ Fig. 1. Longitudinal section of the actuator with the hatched area, in which the hydraulic fluid is located

\section{Fig. 2. Cross section of the actuator with the hatched} area, in which the hydraulic fluid is located

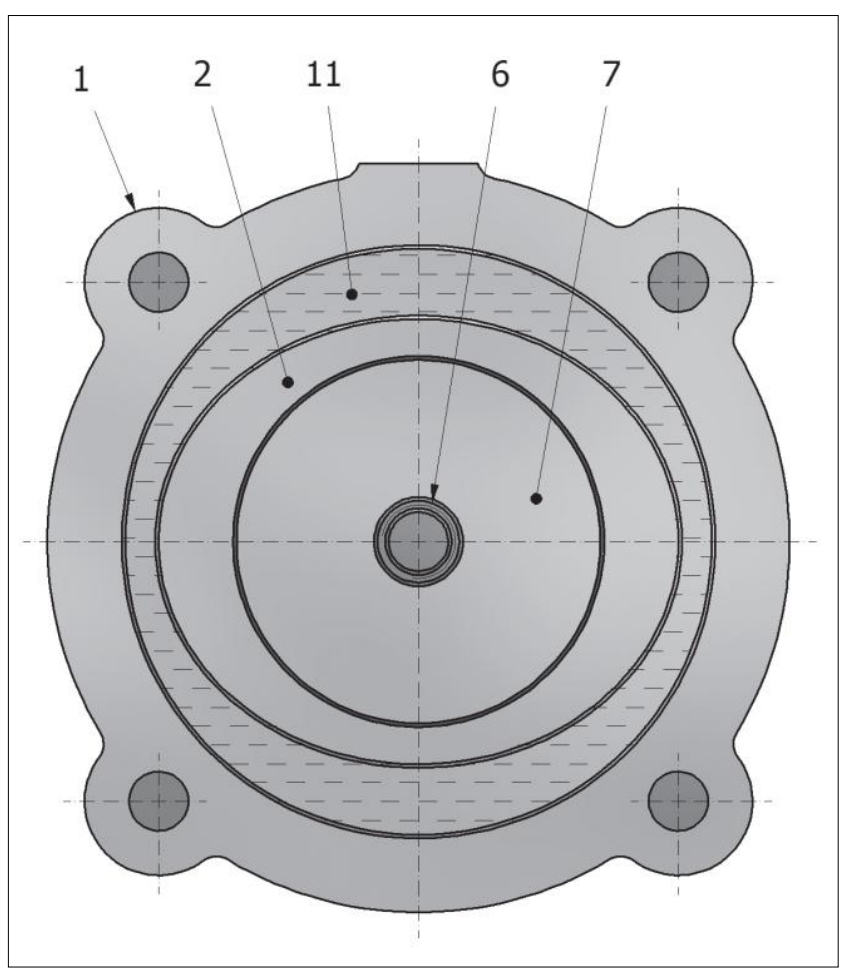

The piston rod (6) has spacers (12) and (13) with a length equal to at least twice the thickness of the inner cylinder flange (2). Their presence is extremely important in terms of construction, because they do not allow the piston (7) with elastic seals (14) to move to a position in which vibrations of the internal cylinder (2) do not occur or occur minimally [6].

The front cover (4) has in the seat: the guide element (15), the scraper ring (16) and the sealing ring (17), in which the piston rod (6) has been routed [6].

In fig. 2, it is shown that the inner cylinder (2) in cross-section has the shape of a ring, the outer contour of this ring is elliptical, and the inner contour - round. The inner cylinder (2) is ended on both sides with flanges 
with a diameter equal to the inner diameter of the cylinder (1), provided with sealing elements (10). The space between the cylinder (1) and the inner cylinder (2) is filled with hydraulic fluid (11) [6].

\section{Principle of operation}

Since the inner cylinder (2) has an elliptical profile from the outside, the wall thickness is uneven along the entire circumference. Thanks to this, due to the increase in pressure of the hydraulic fluid (11), located in the space between the cylinder (1) and the inner cylinder (2), the cylinder deforms unevenly. Applying the variable hydraulic pressure to the cylinder (1) through the hole (9) ensures the correct pressure of the hydraulic fluid (11) and its pulsation necessary to obtain the effect of the vibration of the internal cylinder (2) through its cyclical deformation. Pressure pulses of the hydraulic fluid (11) located in the space between the cylinders (1) and (2) cause the corresponding deformations of the inner cylinder (2). This in turn ensures movement between the sliding surface of the inner cylinder (2) and the seal (14) of the piston (7). This movement reduces the phenomenon of adhesion of seals to sliding surfaces [6].

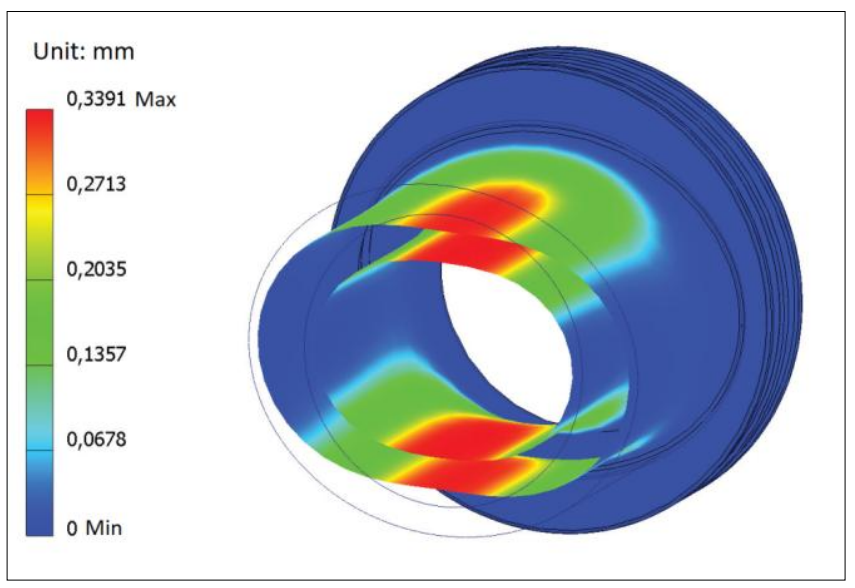

Fig. 3. Internal cylinder deformed under the influence of the hydraulic fluid at a pressure of $10 \mathrm{MPa}$

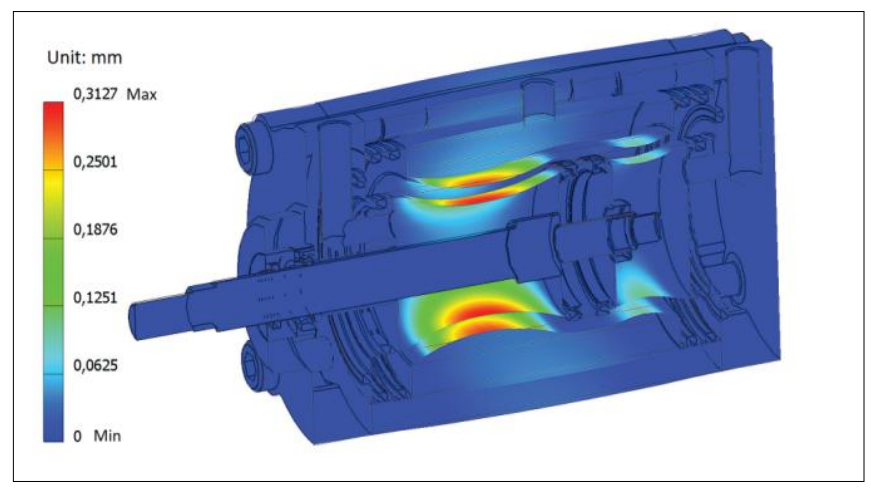

Fig. 4. Pneumatic actuator deformed under the influence of a hydraulic fluid at a pressure of $10 \mathrm{MPa}$

The described effect is especially important at the beginning of the actuator movement, when the phenomenon of adhesion of seals is greatest; the stronger the longer the actuator was stopped. It is possible to start the pulsation of the hydraulic fluid pressure before the actual working motion of the pneumatic actuator, which ensures its smooth start with minimizing the piston displacement in the initial period of the actuator operation. Pressure pulsation is also useful when stopping the actuator, as it ensures greater precision in the final position of the actuator piston [6].

Fig. 3 shows the effect of hydraulic fluid pressure on the inner cylinder (2). The change in pressure of the hydraulic fluid in the space between the cylinder (1) and the inner cylinder (2) is in the range of 0 to $10 \mathrm{MPa}$. On the basis of works $[8,10]$, the optimal frequency of pressure pulsations was determined at $1 \div 2 \mathrm{~Hz}$. The difference in deformation of the cylinder wall can be clearly seen, due to which the mutual position of the sliding surfaces and elastic seals (14) changes, which eliminates their sticking and reduces the stick-slip phenomenon.

Fig. 4 shows the impact of hydraulic fluid pressure on the entire pneumatic actuator assembly. According to the design assumptions, the pressure mainly deforms the inner cylinder, without significantly affecting the other elements of the actuator. This is important to ensure the correct operation of the mechanism.

\section{Summary}

Introduction of relative movement between the piston seal and the cylinder minimizes the phenomenon of adhesion of the seals to the contact surface with the cylinder. This new approach to eliminating or significantly reducing the occurrence of the stick-slip phenomenon involves the use of an active hydraulic system in the construction of a pneumatic actuator. This solution can cause significant complexity in 
the design of the pneumatic actuator supply system. A hydraulic power supply is required to generate pulsation of supply pressure. In addition, changes in the design of the pneumatic actuator are necessary by equipping it with elements of a hydraulic system generating deformations of the pneumatic cylinder.

Such structurally and technologically complex drive may prove to be more expensive to perform compared to a conventional pneumatic actuator. However, the use of an actuator of the proposed structure will be justified in systems, where it is necessary to stop the piston in intermediate positions between the fully extended and retracted piston rod. Obtaining such positions of the pneumatic actuator has always been associated with the need for additional mechanisms increasing the complexity of the structure. By eliminating the stick-slip phenomenon, the proposed construction allows to increase the precision of piston positioning compared to a classic pneumatic actuator.

Design changes presented in the described pneumatic actuator solution necessitate the use of an additional hydraulic power supply unit capable of generating variable hydraulic fluid pressure. However, it is possible to use one power supply for more actuators working in one device. This allows a significant reduction in the costs of applying the new technology in relation to a single actuator.

The proposed mechanism has additional advantages resulting from the use of pneumatic actuators. These are the cheap main working factor, which is air, and the possibility of obtaining smooth movement of the actuator, and even its stopping under the influence of external factors without damaging the actuator and its mechanisms.

\section{REFERENCES}

[1] Andrighetto P.L., Valdiero A.C., Carlotto L. "Study of the friction behavior in industrial pneumatic actuators". ABCM Symposium Series in Mechatronics. 2 (2006): 369-376.

[2] Hennlich. „Uszczelnienia techniczne”, https://www.hennlich.pl/produkty/uszczelnienia-techniczne-1151.html (access: 2014).

[3] Kyoizumi K., Yukishige Fujita Y., Mizumoto I., Iwai Z. "Simple adaptive control for positioning of pneumatic cylinder with adverse stick-slip". IFAC Workshop on Adaptation and Learning in Control and Signal Processing. 37, 12 (2004): 87-92. DOI: https://doi.org/10.1016/S1474-6670(17)31448-9.

[4] Munford P., Normand P. "Mastering Autodesk Inventor 2016 and Autodesk Inventor LT 2016: Autodesk Official Press". Wiley John \& Sons, 2016. System.

„Siłowniki

pneumatyczne", http://www.pneumat.com.pl/silowniki pneumatyczne?gclid=EAIaIQobChMIwePl1LI4QIVioeyCh2RXw6yEAAYASAAEgIDIPD BwE (access: 2017).

[6] Sikorski J. Zgłoszenie patentowe: Siłownik pneumatyczny, nr P.424565 (2018).

[7] Stasiak F. „Zbiór ćwiczeń Autodesk Inventor 2017. Kurs zaawansowany”. ExpertBooks, 2016.

[8] Tran X.B., Yanada H. "Dynamic friction behaviors of pneumatic cylinders". Intelligent Control and Automation. 4, 2 (2013): 180-190, https://doi.org/10.4236/ica.2013.42022.

[9] Trelleborg. „Uszczelnienia dla urządzeń pneumatycznych”, https://www.tss.trelleborg.com/pl-pl/productsand-solutions/pneumatic-seals (access: 2007).

[10] Wakasawa Y., Ito Y., Yanada H. "Friction and vibration characteristics of pneumatic cylinder". The $3^{\text {rd }}$ International Conference on Design Engineering and Science, ICDES 2014. (2014): 155-159. 